\title{
NOTES
}

\section{Plane strain - contact stress distribution beneath a rigid footing resting on a soft cohesive soil}

\author{
A. Patrick S. Selvadurai and R. Harland Kempthorne ${ }^{1}$ \\ Department of Civil Engineering, Carleton University, Ottawa, Ont., Canada K1S 5B6
}

Received February 12, 1979

Accepted September 19, 1979

\begin{abstract}
This note presents an experimental study of the plane strain - contact stress distribution beneath a rigid footing resting on a compacted soft cohesive soil medium. The immediate contact stress distribution was found to be highly dependent on the magnitude of the applied stress relative to the ultimate bearing capacity of the foundation. At low levels of applied stress the contact stresses were substantially higher at regions adjacent to the footing edges. As the applied stresses were increased, the contact stresses achieved a more uniform configuration.
\end{abstract}

Cet article présente une étude expérimentale de la distribution des contraintes de contact en état de déformation plane sous une semelle rigide reposant sur un milieu cohérent mou compacté. La distribution des contraintes de contact s'est avérée fortement dépendante de l'intensité des contraintes appliquées par rapport à la capacité portante de la fondation. A faible niveau de contrainte appliquée, les contraintes de contact sont nettement plus élevées dans les zones proches des bords de la semelle. Lorsque les contraintes appliquées augmentent, la distribution des contraintes de contact devient plus uniforme.

Can. Geotech. J., 17, 114-122 (1980)

[Traduit par la revue]

\section{Introduction}

The study of interaction between structural foundations and the supporting soil media is fundamentally important to both geotechnical and structural engineering. A complete analysis of such an interaction problem should, from a design point of view, provide the following information: (i) the stresses and displacements in the structural foundation; (ii) the contact stresses at the soil-foundation interface; and (iii) the stresses and displacements within the supporting soil medium. If both the soil and the structural foundation exhibit time-dependent material characteristics, then the time-dependent variations of (i) to (iii) should also be furnished from an interaction analysis. A variety of theoretical formulations are employed in the investigation of such interaction phenomena. The accuracy of the theoretical modelling of an interaction problem can be assessed only by recourse to measurements conducted on experimental or full-scale structures. The correlation between theoretical predictions and experimental observations can be examined at a variety of levels; these range from (i) the measurement of the foundation settlement (both differential and total); (ii) the

'Present address: Reservoir Engineering Department, Esso Resources Canada Ltd., Calgary, Alta., Canada. measurement of contact stress distributions at the soil-foundation interface; and (iii) the measurement of total and pore-water pressures at selected locations in the soil medium; to (iv) the measurement of soil displacement and tilt. Admittedly a satisfactory theoretical analysis of a soil-foundation interaction problem should be capable of achieving a correlation with a variety of experimental observations. Detailed accounts of the current state of knowledge in the area of soil-foundation interaction analysis are well documented in the texts by Chen (1975), Desai and Christian (1977), Gudehus (1977), Scott (1978), and Selvadurai (1979). Furthermore, a comprehensive account of both experimental and field studies related to the interaction between structural foundations and soil media is given by Selvadurai (1979); this article places a special emphasis on aspects related to the measurement of contact stresses.

This paper is primarily concerned with an experimental study related to the measurement of the plane strain-contact stress distribution beneath a rigid foundation resting on a compacted soft cohesive soil medium. The term rigid foundation is meant to signify a structural foundation that experiences little or no flexural deformations during the interaction process. Such a situation can occur when the relative rigidity of the foundation-soil system is large. The 
relative rigidity of a soil-foundation system can be characterized in terms of a nondimensional parameter that incorporates the elastic parameters of the soil and the foundation and the dimensions of the foundation. For example, Borowicka (1938) introduced one such parameter,

$$
R=\frac{1\left(1-\nu_{\mathrm{s}}^{2}\right) E_{\mathrm{f}}}{6\left(1-\nu_{\mathrm{f}}^{2}\right) E_{\mathrm{s}}}\left(\frac{h}{b}\right)^{3}
$$

where $E_{\mathrm{s}}, \nu_{\mathrm{s}}$ and $E_{\mathrm{f}}, \nu_{\mathrm{f}}$ are the elastic constants of the soil medium and the foundation respectively; $h$ is the thickness of the foundation; and $2 b$ is its width. A uniformly loaded foundation deformed under plane strain conditions will behave as a rigid foundation provided $R$ is greater than approximately $\pi / 3$. The state of plane strain is a mathematical idealization that is employed to facilitate the solution of certain complex problems in engineering. The exact mathematical restrictions required for the existence of plane strain conditions are rarely realized in practice. The plane strain approximation, however, can be used to examine the behaviour of certain regions of structural foundations and other geotechnical structures. For example, plane strain conditions may be realized, approximately, at the central region of a uniformly loaded rigid raft foundation with a length to width ratio greater than approximately 5 . Since in rigid foundations the flexural response is excluded, the study of the interaction of this class of foundations and soil media provides a valuable opportunity to examine, relatively conveniently, the behaviour at the soil-foundation interface. In practice the interface between the foundation and the soil medium can exhibit a variety of interface phenomena ranging from complete adhesion (or bonded) to completely frictionless (or smooth) with Coulomb friction or finite friction occupying intermediate positions.

The investigation described herein primarily concentrates on the measurement of the normal contact stress at the interface of a rigid foundation resting in frictionless contact with a compacted soft clay medium. The testing is restricted to a state of plane strain deformation. The development of contact stresses at the interface is discussed in relation to the level of applied stress. The influence of time dependence on the contact stress distribution is also investigated.

\section{The Plane Strain Apparatus and Materials}

The soil used in the main test was a remolded Leda clay obtained from a pit owned by the Dochart Brick and Tile Company near Arnprior, Ontario, and having the basic properties outlined in Table 1 . The
TABLE 1. Clay properties

\begin{tabular}{lc}
\hline \hline Soil density $\left(\mathrm{kg} / \mathrm{m}^{3}\right)$ & 1835 \\
Angle of internal friction $(\mathrm{deg})$ & $8-11$ \\
Cohesion, $c_{\mathrm{u}},(\mathrm{kPa})$ & $13-16$ \\
Water content $(\%)$ & $39 \pm 1$ \\
Degree of saturation $(\%)$ & $98 \pm 2$ \\
Liquid limit $(\%)$ & 48 \\
Plastic limit $(\%)$ & 24 \\
Specific gravity & 2.81 \\
Void ratio, $e_{0}$ & $1.12-1.17$ \\
Young's modulus (measured) $(\mathrm{kPa})$ & $5000-10000$ \\
Young's modulus (inferred) $(\mathrm{kPa})$ & $500 c_{\mathrm{u}}$ \\
Compression index, $C_{\mathrm{c}}$ & 0.31 \\
Coefficient of consolidation, $c_{\mathrm{v}},\left(\mathrm{mm}^{2} / \mathrm{s}\right)$ & $0.04-0.06$ \\
\hline
\end{tabular}

properties of sensitive marine clay from the St. Lawrence lowlands have been studied extensively by many authors (see, for example, Mitchell 1970; Bozozuk and Leonards 1972) but these results are not directly applicable to the current investigation. The properties of the material were more representative of a normally consolidated clay. The clay was broken into pieces smaller than $10 \mathrm{~mm}$, extruded through a pug mill into $76 \mathrm{~mm}$ diameter cylinders, 0.3-0.4 m long, and placed in the plane strain apparatus, a sketch of which is shown in Fig. 1. As the clay was extruded it was placed in the upright test tank with each layer uniformly tamped with a $5 \mathrm{~kg}$ hammer. Although the extruded clay had a degree of saturation of over $98 \%$, the total average degree of saturation of the soil in the tank would be reduced if the air voids between the $76 \mathrm{~mm}$ diameter clay cylinders were not filled. At a water content of $39 \%$ the clay was soft enough to be molded in place. To further remove any small air cavities in the clay bed, a surcharge of $42 \mathrm{kPa}$ was applied uniformly over the top of the test tank for a period of 7 days. Since the surcharge loading resembles a one-dimensional compression test with Poisson's ratio equal to 0.5 , there should be no immediate elastic settlement. The immediate compression of the top surface was $21.3 \mathrm{~mm}$, due to the reduction in air cavities. Drainage was allowed to take place at the surface of the test tank and a consolidation settlement of $8.66 \mathrm{~mm}$ occurred. The final thickness of the clay stratum was approximately $1 \mathrm{~m}$.

The clay properties measured in Table 1 were based on samples taken from the test tank following completion of the experiment; i.e., the clay was in a remolded and compacted state. The angle of internal friction was obtained from unconsolidated undrained triaxial tests and direct shear tests. The Young's modulus has been based on a reload modulus, $E_{\mathrm{r}}$, where, in unconsolidated undrained triaxial tests, the load was cycled at least six times up to a stress level 


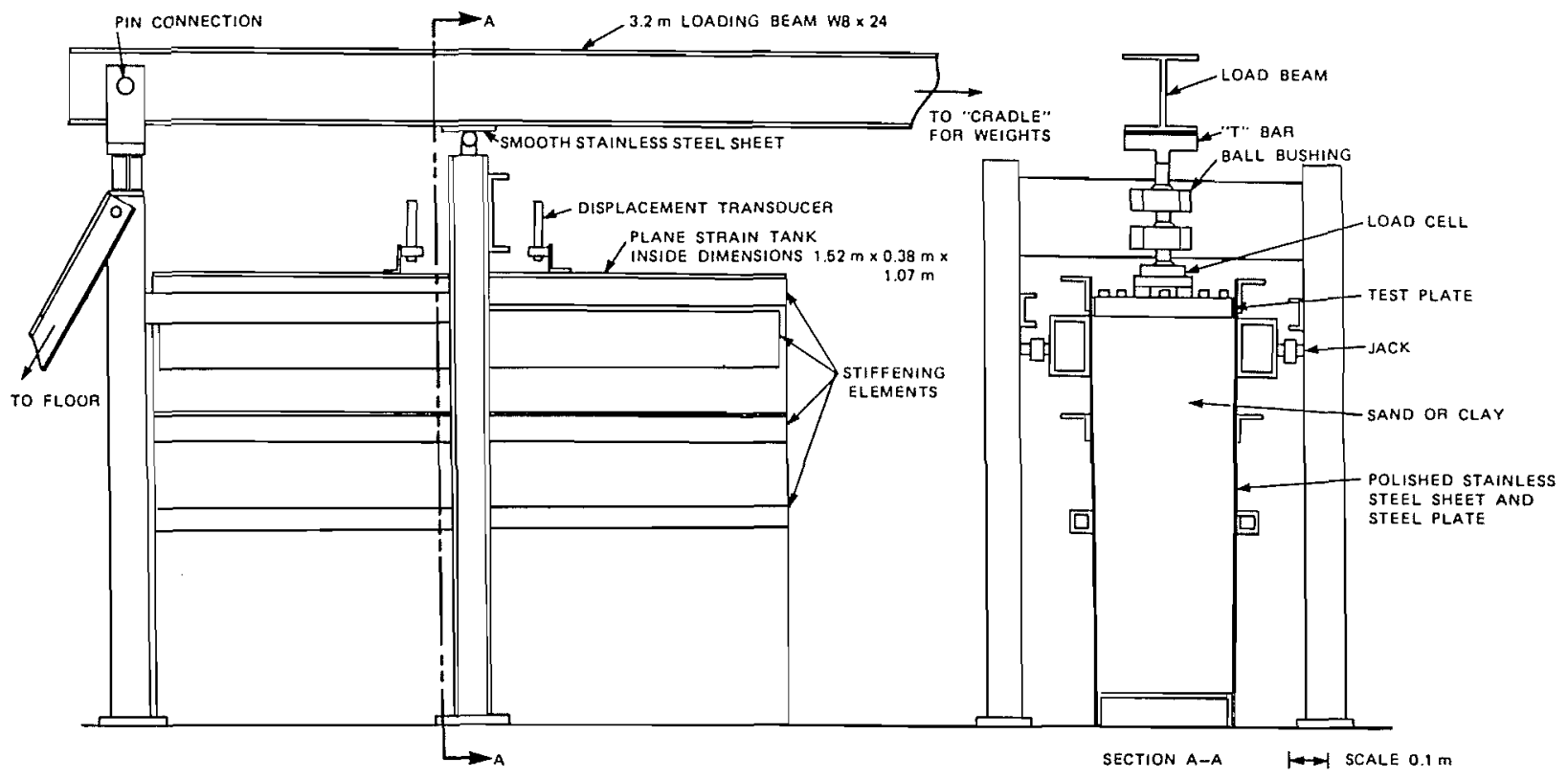

FIG. 1. Diagram of test tank and load apparatus.

of about one half the maximum deviatoric stress. The $E_{\mathrm{r}}$ value was taken as the slope of the tangent occurring on the loading of the final cycle, at a stress level of about one half of the previous cyclic stress increment. The value of cohesion, $c_{\mathrm{u}}$, was obtained from direct shear tests and in situ vane tests. The compression index, $C_{\mathrm{c}}$, and coefficient of consolidation, $c_{\mathrm{v}}$, were obtained from one-dimensional consolidation tests.

The inside walls of the test tank were lined with polished stainless steel, coated with a $0.1 \mathrm{~mm}$ layer of silicone vacuum grease; this procedure was similar to that adopted by Burland and Roscoe (1969). The use of a layer of light oil and a thin sheet of plastic in subsequent tests was found to considerably reduce the side wall friction.

A stress-relieved $377 \mathrm{~mm}$ square steel plate, $51 \mathrm{~mm}$ thick, weighing $55 \mathrm{~kg}$, was used to model the "rigid" foundation. The plate was machined to accommodate 16 pressure cells (see Fig. 2). Their locations were chosen with a view to providing a centre line contact stress distribution from six different locations; the other 10 pressure cell locations were chosen to check the assumption of uniformity of the contact stress along the axis of the strip footing. The base of the plate was milled to a fine finish, ensuring that the plate surface was both plane and smooth.

The pressure transducers used to measure the contact stress were produced by Kulite Semiconductor Products, New Jersey (model number IPT 750-100). Each transducer was a half-bridge piezoresistive device having two active strain gauge elements bonded directly to the sensitive stainless steel diaphragm. The working stress range of the transducer was $0-690 \mathrm{kPa}$ and the error of combined nonlinearity, hysteresis, and repeatability was given as a maximum of $\pm 0.5 \%$ of the full-scale output. Calibration over a narrower range of pressures reduces the error as a function of full-scale output. All tests were performed in a humidity- and temperaturecontrolled room to minimize the effect of these changes on the measuring system.

One phase of the investigation was devoted to examining the effects of the time-dependent behaviour of the cohesive soil on the contact stress distribution. For this reason it was imperative that the load remain constant over the duration of the test. Then, if there were any observable changes in the contact stress, these could be attributed to the time-dependent response of the soil rather than any variation in the applied load. The loading apparatus consisted of a cantilevered beam with a pin connection at one end and a "cradle" for weights at the free end, as shown in Fig. 1. The magnitude of the applied load could be varied by changing weights in the cradle. This method of load application does not possess the degree of flexibility of some other tech- 


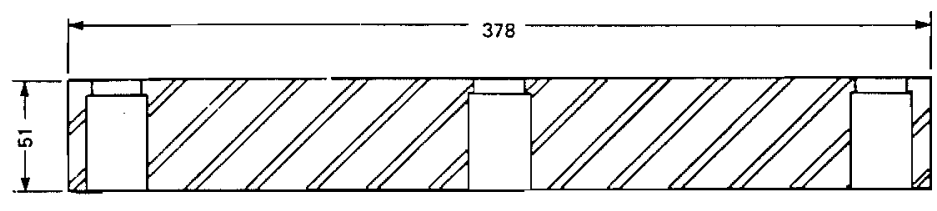

SECTION A-A

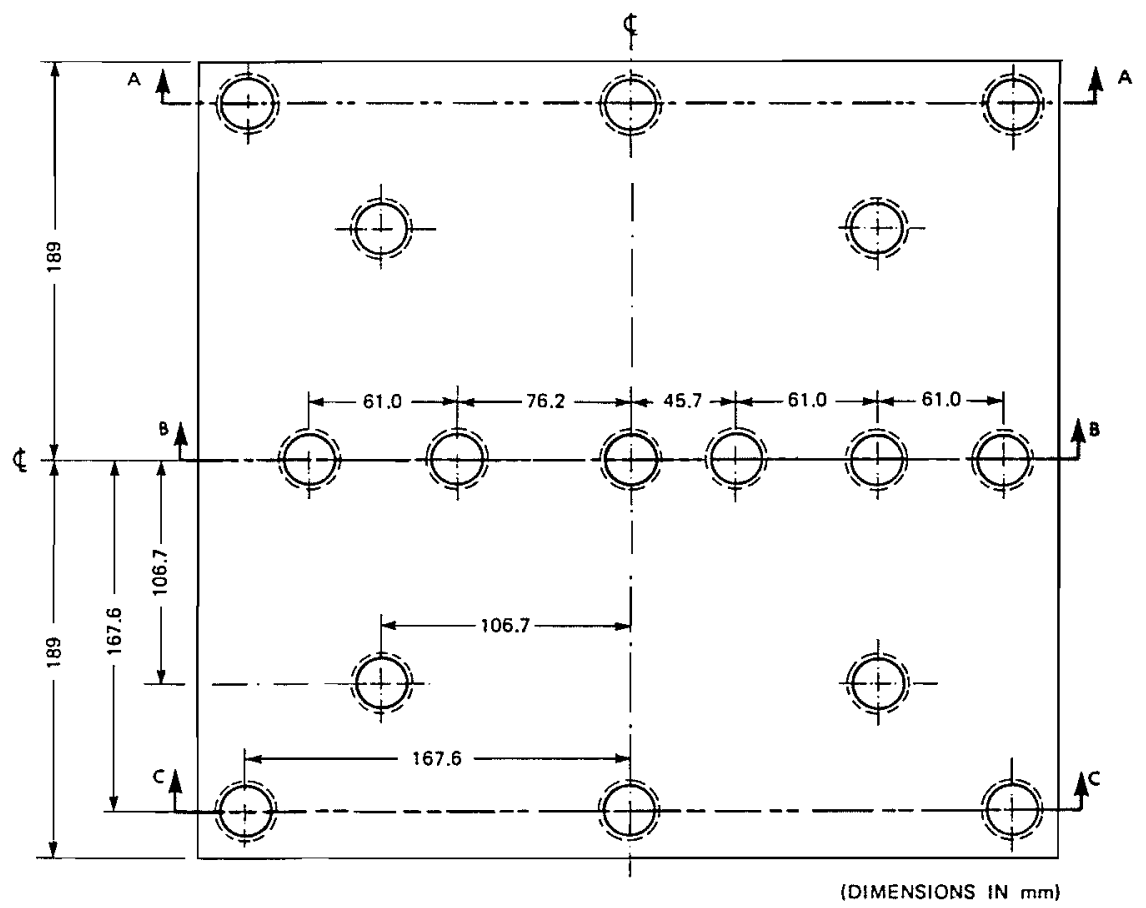

FIG. 2. Diagram of rigid steel test plate.

niques (such as hydraulic jacks), but it does possess the significant advantage of ensuring that the static load remains constant with time.

The load was transferred to a T-bar kept aligned throughout the test by two precision ball bushings. The T-bar was attached rigidly to a $44500 \mathrm{kN}$ capacity load cell positioned above the test plate. The load cell measured the load increment applied directly to the rigid test plate by the cantilevered beam. The settlement of the plate was measured with five linear variable displacement transducers with a stroke range of $\pm 75 \mathrm{~mm}$.

The measuring and data acquisition system consisted of a 40 channel digital strain indicator and recorder. It was capable of automatically recording, at various time intervals, the output of the 16 pressure transducers, 5 linear variable displacement trans- ducers, and the $44500 \mathrm{kN}$ capacity load cell. A comprehensive account of the material parameters, the apparatus, and the test procedures associated with this investigation is reported elsewhere (Kempthorne 1978).

\section{Test Results}

The immediate load-settlement relationship of the plate resting on the compacted soft cohesive soil layer is illustrated in Fig. 3. The relatively steep initial load-deflection response is indicative of the fact that, due to the application and removal of the surcharge, the soft clay soil has acquired a response corresponding to the reloading stress-strain path. The maximum load applied was approximately $60 \%$ of the bearing capacity of the foundation $\left(q_{\mathrm{u}}=5.14 c_{\mathrm{u}}=85 \mathrm{kPa}\right)$. The displacement corresponding to maximum ap- 


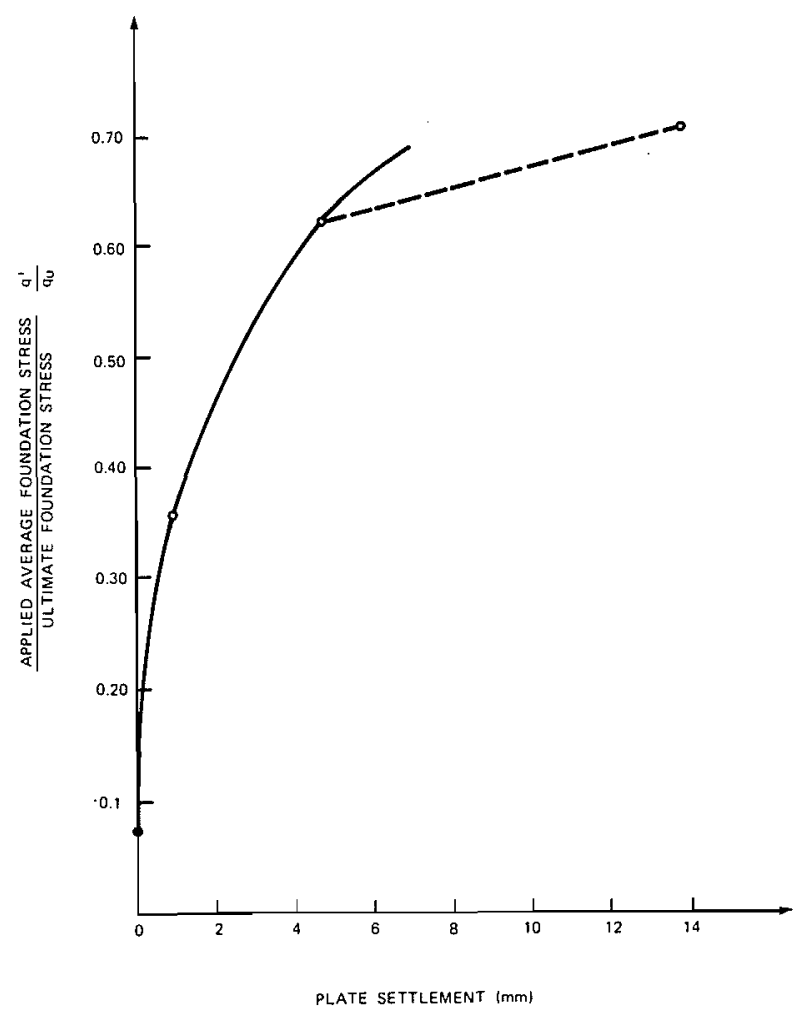

FIG. 3. Plate settlement during first plane strain test.

plied stress appears to deviate considerably from the initial load-deflection response. Whether or not this displacement includes an initial "creep effect" of the soil is open to speculation.

The immediate contact stress distribution is shown in Fig. 4. The contact stress distribution produced by the six centre pressure transducers in line B-B of Fig. 2 is of prime importance. The supplementary pressure transducers positioned around the plate indicated that friction was present between the clay and side walls. Under ideal frictionless conditions, the contact stress distribution along the length of the strip footing would be uniform. The observed contact stresses along $\mathrm{A}-\mathrm{A}$ and $\mathrm{C}-\mathrm{C}$ were up to $50 \%$ higher than the average applied contact stress but the effect appeared to be very localized. The average contact stress along axis B-B was therefore lower than the applied contact stress by about $10 \%$. The ratio $q_{z} / q_{0}$ given in Fig. 4 is the ratio of the measured contact stress to the average contact stress of the centre region of the plate with the effects of the edge friction removed.

The immediate contact stresses are dependent on the magnitude of the applied load relative to the bearing capacity of the soil. For the duration of the test, the contact stresses were higher at the edge than at the centre region, but as the load was increased, the contact stress distribution became more uniform. This is illustrated in Fig. 4 where it is shown that the edge contact stress reduces as the applied stress increases from 4.1 to $27.6 \mathrm{kPa}$.

The load was allowed to remain on the plate for a 5 week period. Throughout this time, the observed contact stress distribution fell within the range observed in Fig. 5. The edge stresses are shown to be between 15 and $30 \%$ higher than the average contact stress. The middle region is between 80 and $95 \%$ of the average. The important observation regarding the time dependence of contact stresses is that there is no substantial redistribution of the high edge stresses to the centre during consolidation, but neither is there a trend toward higher edge stresses. The major readjustment of the contact stress distribution occurred within the first $24 \mathrm{~h}$, after which the changes were relatively small. These fluctuations are within the accuracy of the measuring system.

Another test was performed with the plane strain apparatus wherein the thickness of the clay layer was reduced to $0.5 \mathrm{~m}$. The thinner clay layer will tend to increase the magnitude of the centre contact stress but Tsytovich (1976) showed that changing the layer thickness to strip width ratio from 2.5 to 1.25 will result in less than a 5\% increase in centre contact stress. A thin plastic sheet and light layer of oil helped to reduce the side wall friction considerably. The load was applied in three stages, and is illustrated in Fig. 6.

The summation of the incremental contact stress distribution is shown in Fig. 7. At low stress levels, the contact stress was substantially higher at the edge than at the centre. As the load was increased, the contact stress distribution became more uniform. Relating the load to the bearing capacity of over $80 \mathrm{kPa}$, the contact stress distribution appears to be higher at the edges even for factors of safety less than 2. Based on the experiments conducted (although limited), it becomes evident that, at working stress levels, the edge contact stresses will be substantially higher than their central values.

\section{Conclusions}

It has been observed in the past, and in this investigation, that the edge contact stresses are limited to a finite value because of either plastic yielding of the soil or corner curvature of the foundation (see, e.g., Brown 1968; Chen 1975; Selvadurai 1979). A 


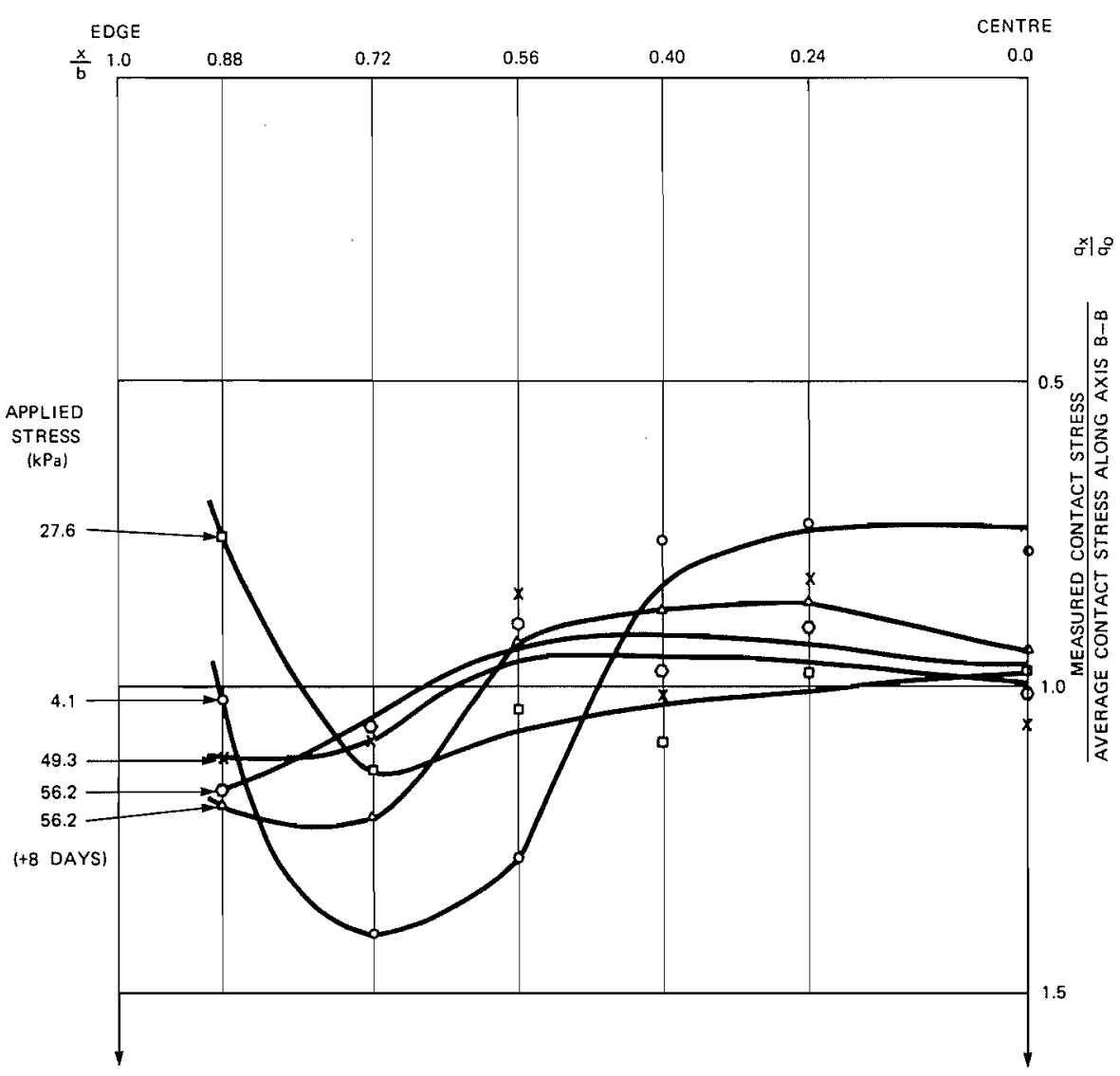

FIG. 4. Initial normalized contact stress distributions during first test on clay.

comparison can be made with the predicted contact stress distribution for a rigid strip footing with plastic yielding at the edges, as proposed by the approximate analyses of Schultze (1961) and Zeevaert (1972). Both methods are essentially the same for a purely cohesive material except for variations in the magnitude of the limiting edge stress. Schultze (1961), in agreement with Terzaghi (1943), assumes that the maximum edge stress is fixed at a value equal to the average bearing capacity of the foundation (i.e., $\left.5.14 c_{\mathrm{u}}\right)$. As the applied stress increases, the centre region of the foundation has an increase in contact stress whereas the edge stress remains constant. Zeevaert (1972) assumes that with a surface foundation, the edge contact stress is limited to $1.5 c_{\mathrm{u}}$, or only about one third of the value chosen by Schultze (1961).

Schultze's (1961) concept is illustrated in Fig. 7. Line (1) represents the contact stress distribution for a rigid strip footing on an elastic half-space (Selvadurai 1979). Line (2) is the result of assuming a bear- ing capacity of $81 \mathrm{kPa}$ and average applied total stress of $56 \mathrm{kPa}$. Lines (3) and (4) were computed from the observed maximum and minimum edge contact stresses in the plane strain test, to be compared with the observed contact stress distributions. Line (5) is a uniform contact stress distribution that would have been computed on the basis of the maximum edge stress as derived from Zeevaert's (1972) analysis. Zeevaert's use of $1.5 c_{u}$ as the maximum edge contact stress appears to be the lower limit that can be expected. Since Schultze's use of $5.14 c_{u}$ predicts higher edge contact stresses than were observed in these experiments, the range of edge contact stresses will probably lie between $1.5 c_{u}$ and $3.0 c_{u}$.

The predicted contact stress distributions in Fig. 7 depend on the assumptions regarding the maximum edge stresses that will occur. Schultze (1961) relates this value to the bearing capacity whereas Zeevaert (1972) uses a much smaller value. The extent of the local yielding will depend on the shear strength of the soil, but more experiments are required to clearly 


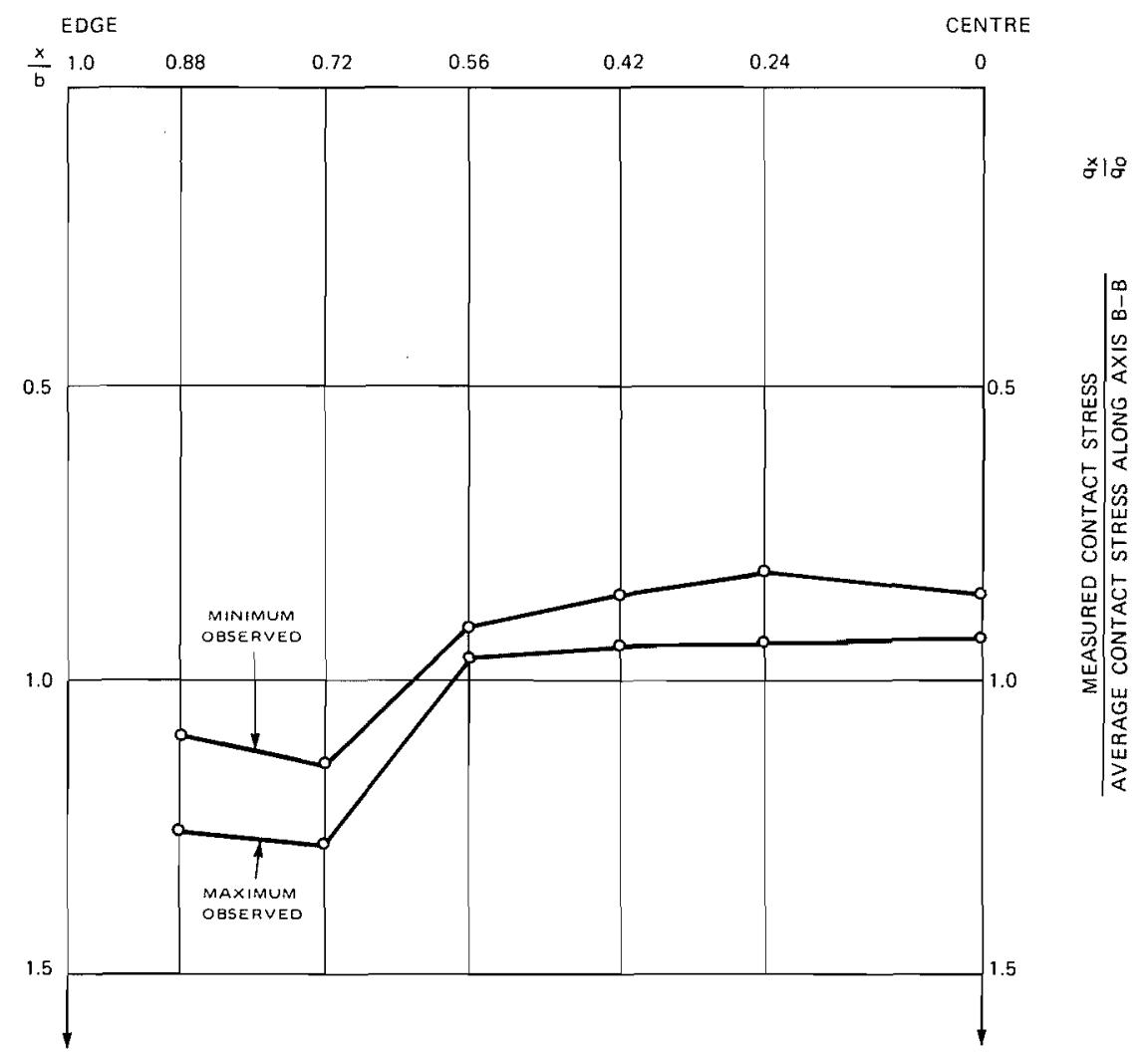

FIG. 5. Normalized contact stress distribution throughout first plane strain test.

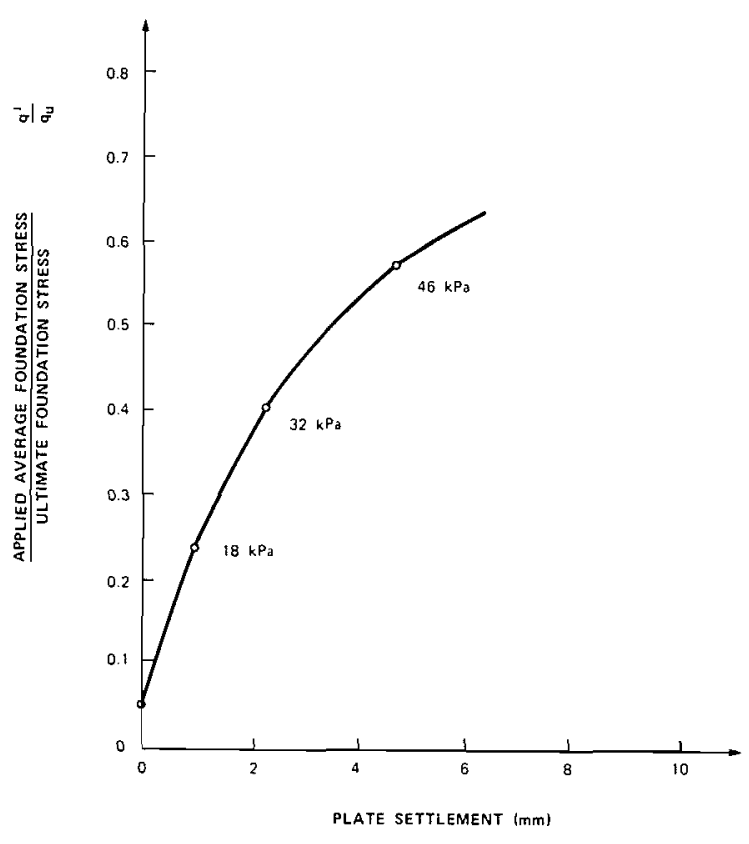

FiG. 6. Plate settlement during second plane strain test. define the relationship between contact stress, shear strength, and magnitude of load. The observations made during this test program can be summarized as follows.

(a) The contact stress distribution observed in this series of experiments differs substantially from the assumption of a uniform distribution.

(b) For a cohesive soil medium, the contact stress distribution depends on the magnitude of the applied load relative to the bearing capacity of the foundation.

(c) From the limited number of tests, it is apparent that the magnitude of soil cohesion enables the contact stresses at the edge to be substantially higher than those at the centre region, as predicted by an elastic analysis. Local yielding of the soil at the edge of the foundation becomes an important factor at higher applied stress levels.

(d) The immediate contact stresses can be predicted from the methods of Schultze (1961) or Zeevaert (1972), provided an estimate of the edge contact stress can be made. On the basis of the limited number of tests, the edge contact stress is of 


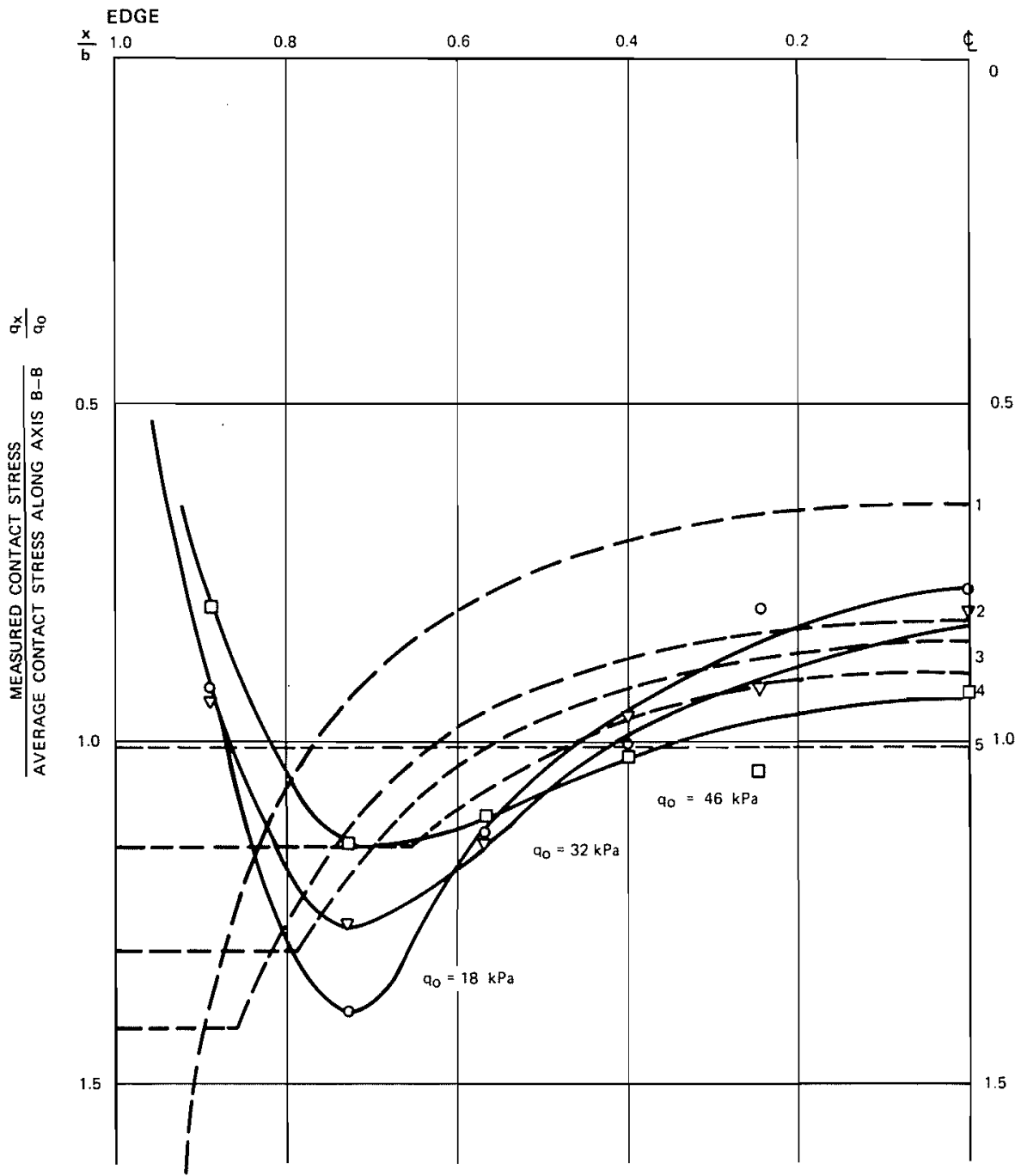

FIG. 7. Contact stress distributions as a function of load magnitude for a rigid strip footing.

the order of $1.5 c_{\mathrm{u}}$ to $3.0 c_{\mathrm{u}}$, i.e., the applied stress at which local yielding occurs.

(e) Throughout the duration of the main test ( 5 weeks) in the plane strain apparatus, the contact stress distribution was found to vary within a narrow band, the shape of which resembled the approximate initial elastic-plastic contact stress. The lack of substantial changes in the shape of the contact stress distribution is thought to be a characteristic of the soft clay used in the experiment.

\section{Acknowledgements}

The work described in this paper forms part of a research study sponsored by National Research Council of Canada grant No. A 3866. One of us
(RHK) acknowledges the research support received from the National Research Council of Canada, in the form of an NRC scholarship.

Borowicka, H. 1938. The distribution of pressure under a uniformly loaded strip resting on elastic isotropic ground. 2nd Congress, International Association for Bridge and Structural Engineering, Berlin, Final Report, Vol. 8(3).

Bozozuk, M., and Leonards, G. A. 1972. The Gloucester test fill. Proceedings, ASCE Specialty Conference on Performance of Earth and Earth-supported Structures, Purdue University, West Lafayette, IN, Vol. 1(1), pp. 299-317.

BRown, P. T. 1968. The effect of local bearing failure on behaviour of rigid circular rafts. Institution of Engineers, Australia, Civil Engineering Transactions, 10, pp. 190-192.

Burland, J. B., and RosCoe, K. H. 1969. Local strains and pore pressures in a normally consolidated clay layer during one-dimensional consolidation. Géotechnique, 19, pp. 335356. 
CHEN, W.-F. 1975. Limit analysis and soil plasticity. Developments in Geotechnical Engineering, Vol. 7. Elsevier Scientific Publishing Co., Amsterdam.

Desai, C. S., and Christian, J. T. 1977. Numerical methods in geotechnical engineering. John Wiley \& Sons Ltd., London, England.

Gudehus, G., editor. 1977. Finite elements in geomechanics. John Wiley \& Sons Ltd., London, England.

KEMPTHORNE, R. H. 1978. Contact stress distributions beneath a rigid strip footing. M.Eng. thesis, Carleton University, Ottawa, Ont.

MitChell, R. J. 1970. On the yielding and mechanical strength of Leda clays. Canadian Geotechnical Journal, 7, pp. 297-312.

SCOT, C. R., editor. 1978. Developments in soil mechanics. Applied Science Publishers, London, England.
SChultze, E. 1961. Distribution of stress distribution beneath a rigid foundation. Proceedings, 5th International Conference on Soil Mechanics and Foundation Engineering, Vol. 6, pp. 807-813.

Selvadurai, A. P. S. 1979. Elastic analysis of soil-foundation interaction. Developments in Geotechnical Engineering, Vol. 17. Elsevier Scientific Publishing Co., Amsterdam.

Terzaghi, K. 1943. Theoretical soil mechanics. John Wiley \& Sons Inc., New York, NY.

Tsyrovich, N. 1976. Soil mechanics. Mir Publishers, Moscow, U.S.S.R.

ZEEVAERT, L. 1972. Foundation engineering for difficult subsoil conditions. Van Nostrand Reinhold Co., New York, NY.

\title{
A documentation of soil failure during the British Columbia earthquake of 23 June, $1946^{1}$
}

\author{
GARRY C. ROGERS \\ Pacific Geoscience Centre, Earth Physics Branch, P.O. Box 6000, Sidney, B.C., Canada V8L $4 B 2$ \\ Received April 9, 1979 \\ Accepted August 30, 1979
}

\begin{abstract}
All examples of soil failure, other than landslides, that could be identified as occurring during the magnitude 7.2 Vancouver Island earthquake of 23 June, 1946 have been documented. Slumping and liquefaction were common and caused a significant proportion of the earthquakerelated damage. Liquefaction occurred up to a distance of $100 \mathrm{~km}$ from the epicenter, a distance that agrees well with a previously established empirical relationship.
\end{abstract}

On a relevé tous les exemples de rupture des sols, autres que les glissements de terrain, dont on a pu établir qu'ils s'étaient produits lors du tremblement de terre de magnitude 7.2 sur l'île de Vancouver le 23 juin 1946. Des affaissements et des phénomènes de liquéfaction ont été nombreux et ont produit une grande partie des dommages reliés au tremblement de terre. La liquéfaction s'est développée jusqu'à une distance de $100 \mathrm{~km}$ de l'épicentre, distance qui concorde bien avec les relations empiriques établies précédemment.

Can. Geotech. J., 17, 122-127 (1980)

[Traduit par la revue]

On 23 June, 1946 a magnitude 7.2 earthquake occurred in the central Vancouver Island region. The epicenter and isoseismal map are shown in Fig. 1 (from Rogers and Hasegawa 1978). Damage was remarkably light due to the sparse population in the epicentral region and the predominance of low-rise wood frame structures, which are generally very earthquake resistant. There were many examples of masonry failure, mostly falling chimneys, which would have caused numerous deaths and injuries had

\footnotetext{
${ }^{1}$ Contribution from the Earth Physics Branch, No. 813.
}

the earthquake occurred at some other time than 10:15 on a Sunday morning. Although it is not generally known, there were also many examples of soil failure: landslides, slumping, and liquefaction, which caused considerable damage and which resulted in the only death during the earthquake. (A man was drowned when a wave caused by a slump into the sea overturned his small boat.)

There were many hundreds of landslides caused by this earthquake in areas experiencing modified Mercalli intensities of VI and greater. Most occurred on steep terrain away from populated areas. Mathews 